\title{
General practice in the Nordic countries
}

\author{
KIM ROSE OLSEN ${ }^{1, *}$ \\ ANDERS ANELL ${ }^{2}$ \\ UNTO HÄKKINEN $^{3}$ \\ TOR IVERSEN ${ }^{4}$ \\ THORHILDUR ÓLAFSDÓTTIR ${ }^{5}$ \\ MATT SUTTON $^{6}$
}

\author{
${ }^{1}$ Centre of Health Economics Research, University of Southern Denmark \\ ${ }^{2}$ Department of Business Administration, Lund University, Sweden \\ ${ }^{3}$ Centre for Health and Social Economics, National Institute for Health and Welfare, Helsinki, Finland \\ ${ }^{4}$ Department of Health Management and Health Economics, University of Oslo, Norway \\ ${ }^{5}$ Department of Economics, University of Iceland \\ ${ }^{6}$ Manchester Centre for Health Economics, University of Manchester, UK
}

\begin{abstract}
Background: General practice systems in the Nordic countries share certain common features. The sector is based on the Nordic model of a tax-financed supply of services with a political objective of equal access for all. The countries also share the challenges of increased political expectations to deliver primary prevention and increased workload as patients from hospital care are discharged earlier. However, within this common framework, primary care is organized differently. This is particularly in relation to the private-public mix, remuneration systems and the use of financial and non-financial incentives. Objective: The objective of this paper is to compare the differences and similarities in primary care among the Nordic countries, to create a mapping of the future plans and reforms linked to remuneration and incentives schemes, and to discuss the pros and cons for these plans with reference to the literature. An additional objective is to identify gaps in the literature and future research opportunities. Results/Conclusions: Despite the many similarities within the Nordic health care systems, the primary care sectors function under highly different arrangements. Most important are the differences in the gate-keeping function, private versus salaried practices, possibilities for corporate ownership, skill-mix and the organisational structure. Current reforms and political agendas appear to focus on the side effects of the individual countries' specific systems. For example, countries with salaried systems with geographical responsibility are introducing incentives for private practice and more choices for patients. Countries with systems largely based on private practice are introducing more monitoring and public regulation to control budgets. We also see that new governments tends to bring different views on the future organisation of primary care, which provide considerable political tension but few actual changes. Interestingly, Sweden appears to be the most innovative in relation to introducing new incentive schemes, perhaps because decisions are made at a more decentralised level.
\end{abstract}

JEL classification: D61, H51, I12, I18

Key words: general practice, remuneration, primary care, incentives, Nordic countries

\footnotetext{
* Correspondence to: Kim Rose Olsen, Campusvej 55, 5230 Odense. E-mail: krolsen@ sam.sdu.dk dx.dio.org/10.5617/njhe.2801
} 


\section{Introduction}

\subsection{The Nordic model of health care}

Health care in the Nordic countries is public and is primarily financed through taxes. Health care expenditures represent approximately $9 \%$ to $11 \%$ of the gross domestic product (GDP). Denmark represents the highest share, and Finland represents the lowest.

Health policy in the Nordic countries is organised around the objective of good and equal access to health care for the entire population. The role of primary care is being defined in various ways but may be summarised by four key objectives (Starfield, 2005); i) serve as citizens first point of contact and entry to the health care sector ii) holds the responsibility for the largest share of preventive care, diagnostics and treatment iii) focus on the patients abilities and total health care needs rather than single diagnoses iv) refer to specialised care if needed and co-ordinate the care supplied by other health professionels.

The Nordic countries are all encountering the same overall challenges of an aging population, decreasing lengths of hospital stay, and the resulting pressures on primary care. The increasing specialization of the hospital sector, the increased prevalence of chronic diseases to be taken care of by primary care and the occurrence of more demanding patients with social rather than medical problems further involves a higher need for primary care capacity. These circumstances may involve a need for changes in the organization of primary care and in the behaviour of primary care health professionals. The economics literature on physician behaviour is largely based on financial incentives and regulation through remuneration schemes (Reinhardt 1999). Hence, this paper addresses the role of financial and non-financial incentives in solving the future challenges in primary care, specifically with a focus on what we can learn from the Nordic countries' experiences.

In the Nordic health care sectors, in which health care is largely perceived as a publicly provided good, the health authorities have, in an increasing manner, introduced market inspired mechanisms to affect the behaviour and effort of health care providers with the overarching objective of achieving more efficiency. Activity based funding as e.g., DRG based payments in the hospital sector have been the rule of the game for more than a decade. However, the recent, more or less worldwide trend in which focus has shifted away from activity towards quality, often introducing incentive mechanisms to encourage providers to certain behaviours. This trend has, to various extents, also been present in primary care, with the UK Quality and Outcomes Framework (QOF), which focuses on pay for performance (P4P) schemes, as the obvious example. However, P4P has, thus far, had a modest impact in the Nordic primary care sector.

Theoretically, there are several advantages and disadvantages to the various incentive mechanisms, and governments often attempt to supplement with regulations that address the potential side effects connected to the system in operation. These regulations may be linked to the manner in which primary care practices are remunerated, organised or incentivized to certain behaviours.

Considering the many similarities of the overall organisation of health care in the Nordic countries, it is striking that the remuneration and incentives schemes of the primary care sector appears to vary substantially among the Nordic countries. Therefore, it is important from a policy perspective to explore whether certain incentive mechanisms are likely to work better than others in publicly financed tax-based systems. One means to do that is to systematically compare the primary care setting among the Nordic countries and map the agenda of future reforms within each country. Such gathering of information offers the possibility of analysing similarities and non-similarities between primary care in the Nordic countries in a manner that can inform policy makers. As an example, future reforms 
are often based on shortcomings within each system because those are based on past experiences with each specific primary care system (Krasnik and Paulsen 2009).

The objective of this paper is to:

- Discuss the pros and cons for the various incentive schemes used in the primary care sector. Because the effectiveness of incentive schemes may depend on the context, it will be discussed in relation to the Nordic context.

- Conduct a systematic comparison of the structure of and use of financial incentives within primary care services in the Nordic countries. Thus, differences and similarities in primary care among the Nordic countries can be highlighted.

- Create a mapping of the future plans and reforms linked to remuneration and incentives schemes for primary care/family doctors in the Nordic countries.

- Identify future research opportunities on the effectiveness of various incentive mechanisms within the context of the Nordic health care system.

This paper is organised as follows. First, we briefly describe the standard financial and non-financial regulations being used in primary care. Because various reviews on this topic exist (Gosden, Forland et al. 2000), this section will be very short. Second, we create a description of the primary care sector that includes its remuneration- and incentive schemes in each of the five Nordic countries (Denmark, Norway, Sweden, Finland and Iceland). Third, recent political agendas and reforms are described; finally we discuss the differences and similarities and establish potential research agendas based on the Nordic primary care sector.

\section{Financial and non-financial regulation in primary care}

Primary care physicians can be salaried public employees or self-employed independent professionals. Independent practitioners typically run practices and are remunerated by the number of citizens they serve (capitation), the number of services they provide (fee for service, FFS) or a mix of these. The hypothesis regarding the effect of the various schemes is moderately obvious; salaried physicians are hypothesised to have lower levels of activity but offer a high degree of budget control for the authorities. Private practice based on FFS may increase the level of activity but adds a risk of the oversupply of services and more slack in relation to budget control. However, there may be positive side effects because primary care physician may reduce referrals to specialised care for services that could be undertaken at lower costs in primary care. Conversely, capitation systems may increase the level of activity compared with salaried physicians; however, compared with FFS, there is a risk that patients are referred more often to specialised care. Regarding total costs, expectations would be that salaried systems has the lowest costs, FFS the highest and capitation systems will be in between.

There is a relatively small body of empirical literature with evidence on the above hypothesis, and often the studies are challenged by the fact that control group design is rarely possible; hence, no causal inference can be drawn. A review of the most recent literature is on the way (Jia et al. 2015), and it is beyond the scope of this paper to make a full literature review but an older Cochrane review, summarises the evidence as follows: "There was some evidence that primary care physicians provide a greater quantity of primary care services under fee for service payment compared with capitation and salary, although long-term effects are unclear. There was no evidence, however, concerning other important outcomes such as patient health status, or comparing the relative impact of salary versus capitation payment" (Gosden, Forland et al. 2000).Regarding the risk of oversupply 
in relation to FFS systems, there is a large body of literature on supplier-induced demand (Evans 1974, Reinhardt 1985, Grytten, Carlsen et al. 1995, Grytten and Sorensen 2001, Richardson and Peacock 2006, Grytten and Sorensen 2007, Peacock and Richardson 2007, Grytten and Sorensen 2008). However, the empirical evidence on the hypothesis is not robust, and there is no firm evidence that physicians induce demand.

The most recent and fastest growing body of literature on financial incentives in primary care addresses the effectiveness of $\mathrm{P} 4 \mathrm{P}$ schemes. A systematic review concludes that no firm conclusion on the effectiveness of P4P can be drawn, basically because the design of the studies is excessively weak (Eijkenaar, Emmert et al. 2013). Regarding the case of the effectiveness of various remuneration schemes, more robust studies are needed.

\section{General practice in the Nordic countries}

In this section, we will provide an overview of the differences and similarities of the organisation and the remuneration of primary care in the Nordic countries.

\subsection{General structure}

The Nordic countries encounter various levels of decentralisation. In Denmark, the health care system is embedded in a decentralized administrative structure consisting of 5 regions and 98 municipalities. In Finland, the system is the most decentralised because 315 municipalities are responsible for arranging and taking financial responsibility for an entire range of health services, which also includes health centres that provide primary health care services. However, the Finnish system is exceptional because primary doctors services are provided to a large extent also by private sector (children are covered by private insurance) and occupational care (working population) funded partly by a social insurance system.

In Sweden, the County Councils are responsible for primary care, and there are relatively large variations in organisation and remuneration schemes among them. Primary care has historically played a relatively limited role in Sweden as opposed to e.g., Denmark and a scarcity of primary care physicians have made citizens accustomed to turn directly to the specialised sector (Anell 2014). In Norway, primary care physicians work on contract with the municipalities based on a national set of capitation and FFS tariffs.

Iceland differs, to an extent from the other countries - mainly due to small size of the population. The state manages the primary health care which is provided at 8 health institutions throughout the country and at the Primary Health Care of the Capital Area (PHCCA) which is an institution operating 15 mutually financed health clinics. Health centres providing primary care outside the capital area are sometimes jointly run with small hospitals or health institutions that are all publicly run, based on fixed budgets. Increased centralization took place in the primary care by the formation of PHCCA in 2006. Previous to the change, primary care was provided by independent practitioners based in health centres.

GPs have a gatekeeping role in Denmark and Norway in that patients are required to register with a GP to obtain a referral to specialist care. In Finland a referral is also needed, but this can be from any doctor, not necessarily a GP. This is not the case in Iceland and Sweden. With the exception of a few county councils where gate-keeping exists, patients in Sweden can go directly to many specialists, so called self-referral. In addition to the lack of formal gatekeeping, this direct access is because of a historical access pattern and a shortage of GPs in general. However, different Swedish counties have other formal and informal restrictions on accessing specialists ${ }^{1}$. As in Sweden, Icelandic patients have the

\footnotetext{
${ }^{1}$ Co-payments to specialist care are higher without a referral and patients may be advised to visit primary care
} first. 
freedom to seek services directly from specialists; it can be assumed that a portion of the primary care is provided at specialists' private practices and emergency care units ${ }^{2}$.

In Denmark and Norway, GPs are self-employed and operate as private practices (although Norway has five percent salaried GPs who are primarily located in remote areas). In Sweden and Iceland, the organizational schemes vary; salaried physicians working at public health care centres are most prevalent, but Sweden is the only Nordic country to allow corporate ownership. In Iceland, after hours and night time services are operated as private practice. In Sweden, most doctors are salaried employees; however, there is a trend towards more private practices, particularly in certain regions were about $50 \%$ of provision is by private practice. This trend has been supported by national regulations since 2010 that encourage freedom of establishment for private providers, competition between primary care providers on equal terms and enhanced patient choice. In Finland, GPs working at health centres are also mainly salaried doctors, although they can either supplement their salary with a fee per consultation according to agreements made at the local level. The occupational care doctor reimbursement system varies between companies, and in private health care, a fee for service is prevalent.

There is a trend towards group practice or multidisciplinary care, with nurses and other health care professionals increasingly involved in care delivery. In many European countries, financial incentives are in place to encourage physician to form group practices. Furthermore, many countries are moving toward a greater use of nurses working alongside doctors. Among the Nordic countries, this trend can particularly be observed in Sweden and Finland. Sweden was one of the first European countries to create nurse-led clinics for patients with long-term conditions such as diabetes and heart failure. Now nurse-led clinics are becoming popular in other countries as well.

\subsection{Remuneration schemes and incentive structures}

Of the Nordic countries under consideration, Finland and Iceland are mainly based on salaried systems, whereas the system in Denmark and Norway are based on blended capitation and FFS remuneration systems with the largest part being on FFS (approximately $70 \%$ ). In Sweden, the remuneration systems vary among county councils; however, the largest share is based on capitation. In addition to being the sole Nordic country that has experience with risk adjusting the capitation, Sweden is also the sole country that has experience with pay for performance. Table 1 below provides a brief overview of the main remuneration and incentives schemes of the Nordic countries.

As noted in the introduction, co-payments for patients is relatively modest but present in all countries except Denmark, in which a co-payment is solely linked to prescription drugs. All the other countries have annual ceilings at various levels but never above 230 euros. However, Denmark, Norway and Sweden all have co-payments for nonregistered patients.

Regarding incentives for operating in rural- and scarcely populated areas, all countries except Iceland have schemes implemented; in Norway, for example, there are cases in which the capitation has additional payments added to it in remote areas. The same principles are used by some Swedish county councils.

\footnotetext{
${ }^{2}$ In Finland, patients have the freedom to seek private specialist service, which is partly reimbursed by the National Health Insurance.
} 


\section{Table 1: $\quad$ Payment schemes and other incentives}

\begin{tabular}{|c|c|c|c|c|c|}
\hline & Denmark & Finland & Iceland & Norway & Sweden \\
\hline FFS-Capitation-Salary & FFS/ Capitation & Salary, FFS & Salary, FFS & FFS/ Capitation & $\begin{array}{l}\text { Varies, but in general } \\
\text { Capitation with some fee-for-visit and P4P }\end{array}$ \\
\hline Co-payment for patients & $\begin{array}{l}\text { Only for } \\
\text { prescription drugs }\end{array}$ & $\begin{array}{l}\text { Health centres: euro } 16.10 \\
\text { or euro } 32.10 \text { annually with } \\
\text { an annual ceiling related to } \\
\text { all public health services. } \\
\text { Occupational care free. } \\
\text { Private doctors' services } \\
\text { patient pays about } 80 \% \text { of } \\
\text { the fee }\end{array}$ & $\begin{array}{l}\text { Yes }- \text { with an annual } \\
\text { ceiling that varies } \\
\text { among age groups } \\
(-18): 225 \text { euro } \\
(18-66): 200 \text { euro } \\
(66-70): 60 \text { euro } \\
(70+): 80 \text { euro }\end{array}$ & $\begin{array}{l}\text { Yes with an annual } \\
\text { ceiling } \\
\text { Around } 230 \text { euro }\end{array}$ & $\begin{array}{l}\text { About } 150 \text { SEK per visit to GP, with } 12 \text { - } \\
\text { month high-cost protection }\end{array}$ \\
\hline $\begin{array}{l}\text { Risk-adjusted } \\
\text { remuneration }\end{array}$ & No - but discussed & No & $\begin{array}{l}\text { No - but plans for risk- } \\
\text { adjusted capitation fees }\end{array}$ & No - no plans so far & $\begin{array}{l}\text { Varies, but usually combination of: } \\
\text { Age, sex, Socioeconomic, ACG, } \\
\text { geographical }\end{array}$ \\
\hline $\begin{array}{l}\text { Special payment for rural } \\
\text { areas or scarcely } \\
\text { populated areas }\end{array}$ & $\begin{array}{l}\text { No } \\
\text { But a few Regional GP } \\
\text { clinics managed by the } \\
\text { Regions }\end{array}$ & $\begin{array}{l}\text { Payments are locally } \\
\text { negotiated }\end{array}$ & No & $\begin{array}{l}\text { Some additions to } \\
\text { capitation + salaried } \\
\text { GPs }\end{array}$ & Yes, in some CC \\
\hline $\begin{array}{l}\text { Differences in payment } \\
\text { for list-patients and non- } \\
\text { list patients }\end{array}$ & Yes (2\% non-listed) & None & None & $\begin{array}{l}\text { Yes - some difference } \\
\text { in co-payment }\end{array}$ & $\begin{array}{l}\text { Yes, fee for service or agreements between } \\
\text { practices if not registered }\end{array}$ \\
\hline $\begin{array}{l}\text { Ceilings of payments, } \\
\text { kinks in payment } \\
\text { schemes. Other } \\
\text { mechanisms for cost } \\
\text { containment }\end{array}$ & $\begin{array}{l}\text { Yes, national ceiling } \\
\text { introduced in } 2011 . \\
\text { Collective punishment }\end{array}$ & None & None & None & $\begin{array}{l}\text { Stockholm had ceiling in FFS component. In } \\
\text { most CC } 80 \% \text { or more is capitation, so cost } \\
\text { control is taken care of. }\end{array}$ \\
\hline $\begin{array}{l}\text { Specific fees to target } \\
\text { prioritised activities }\end{array}$ & Yes - many & None & None & Some & Some \\
\hline Use of $\mathrm{P} 4 \mathrm{P}$ & None & None & None & None & Yes, in all but $1 \mathrm{CC}$. \\
\hline Integrated Care & $\begin{array}{l}\text { Local projects in a few } \\
\text { municipalities }\end{array}$ & $\begin{array}{l}\text { Local projects in some } \\
\text { regions }\end{array}$ & No & No & $\begin{array}{l}\text { Some county councils have special payment } \\
\text { for integrated services }\end{array}$ \\
\hline Other incentive schemes & $\begin{array}{l}\text { Experience with use of } \\
\text { EHR and quality } \\
\text { feedback to GPs on } \\
\text { relative performance }\end{array}$ & None & None & None & $\begin{array}{l}\text { Quality feedback in most CC, but ambitions } \\
\text { vary. Use of EHR. Patient reports (national } \\
\text { surveys) published online that makes } \\
\text { comparison between practise possible. }\end{array}$ \\
\hline
\end{tabular}


As noted in section 2, one of the risks of private practice is an oversupply of services. Denmark and some county councils in Sweden have introduced ceilings on the FFS component. In Denmark, for example, this ceiling works in the manner that excess FFS spending in a given year is deducted from the next year's plan increases in fees. This mechanism can be viewed as collective punishment of individual behaviour because the excess FFS may be driven by a subgroup of the practices.

Denmark and Sweden have experience of the use of electronic health records (EHR) and feedback on quality performance. This is an interesting development that has been shown to have an effect on the primary care quality in certain US settings. Kolstad (2013) for example shows that the effect of feedback on performance to surgeons was four times larger than the effect of financial incentives. Reed et al. (2013) show that the use of EHR in Californian general practices have reduced the hospitalization rate for diabetes patients by $10 \%$. This is a larger reduction than what has been shown for the QOF (Harrison, Dusheiko et al. 2014).

\section{Challenges, future plans and reforms}

The Nordic countries are all encountering the same overall challenges of an aging population, decreasing lengths of hospital stay, and the resulting pressures on primary care. The increasing specialization of the hospital sector, the increased prevalence of chronic diseases to be taken care of by primary care and the occurrence of more demanding patients with social rather than medical problems further involves a higher need for primary care capacity. In addition to these common issues, each country encounters certain challenges related to specific circumstances. Below, we provide an overview of what we believe are the most current and pivotal challenges encountered by the sector in each country and which are currently receiving political attention. Here we concentrate only the latest reforms. Earlier reforms have been discussed by e.g. Krasnik and Paulsen 2009.

\subsection{Denmark}

The Danish primary care sector has been stable without major reforms since the municipality reform in 2007. However, the period from 2012 to 2015 has been one of high political tension. Two episodes are highlighted. First, in 2012, the negotiations for the national contract, which define work conditions as well as the capitation and FFS tariffs, were devolved to the Regions. The Regions accused the association of GPs of not wanting to negotiate on efficiency measures comparable to other parts of health care and of unwillingness to increase the transparency of activity and quality measures. On the other side, the GP Association accused the Regions of wanting to control every detail of their work. A tense political struggle ensued after the breakdown, and many of the key issues in the negotiations remained unsolved. For example, the discussions on increased and differentiated capitation were not carried forward.

Second, a large scale initiative to implement a quality improvement program based on Electronic Health Records was withdrawn because of evidence that the data protection authorisations had not been adequate. This has caused major political tension within the Association of General Practitioners, and it is uncertain whether they can agree on the agenda for negotiating the national contract.

In 2014, the left-wing government announced in their health care program that they wanted to invest in primary care by introducing preventive visits for vulnerable groups and to experiment with new remuneration systems based on pay for performance and differentiated capitation. When the right wing government took over in the summer of 2015, they reversed certain of the former government's idea for the future primary care sector; 
among other things, this included the prevention programme for vulnerable patients. Experiments with new remunerations schemes were however, carried forward in a research project.

In sum, regarding the political situation in Denmark, there is political pressure to increase the control and transparency of activity and quality in private practice. This pressure threatens the autonomy of the GPs; major struggles for achieving agreement on the National Contract are ahead.

\subsection{Norway}

There is a significant deficit of information on the patterns of care and outcomes in primary care. There are certain broad measures of primary care in Norway, including prescribing patterns and hospital admissions for chronic conditions; however, little is known about the quality of care at a more local level. There is virtually a complete absence of information at local level regarding the quality of primary care services. Norway has no information infrastructure at the local or national level to systematically collect a dataset that would allow GPs, patients and authorities to benchmark quality and performance against peers or against national guidelines. In addition, most Norwegian GPs would likely not be able to rapidly produce an up-to-date register of, for instance, patients with diabetes.

The coordination reform was initiated in Norwegian health care from 2012. The idea is to implement measures that reallocate resources from specialized care to primary care and long-term care and to improve the coordination between care providers for patients with chronic diseases. Currently there are few strong incentives for GPs to deliver the Coordination Reform's vision of integrated, proactive and community focused care. It is considered to be a major challenge to encourage GPs to take responsibility for the coordination of care to their patients.

Holte et al. (2015) find that job satisfaction has decreased and many GPs have preferences for shifting to salaried contracts. They suggest that one reason might be the coordination reform ambition of more out of office - and interdisciplinary work, increased accessibility, meeting attendance, reporting and administrative duties reduce the autonomy of the privately practising GPs.

The government published a white paper on primary health care in the spring of 2015 (Melding til Stortinget nr. 26 (2015)). The main proposal offered is to establish multidisciplinary primary care teams to address the challenges of the increase in chronic diseases and the various needs of the elderly population. The document is very general with few specific proposals for the organization and financing of the teams. The details and possible implementation of primary care teams are likely to be a main topic in the policy debate regarding primary care in Norway in the ensuing years.

\subsection{Sweden}

Reforms involving choice and privatization, initiated in certain county councils in $2007 / 2008$ and becoming a national requirement in 2010, have increased the number of practices and improved access to primary care in several county councils. However, studies indicate that access has improved more for the general population, whereas patients with significant needs and individuals in socioeconomically poor areas have experienced minor improvements (Anell 2015). The new Social Democratic government that entered office in the fall of 2014 initially developed plans to reverse the law from 2010, but these plans were abandoned by fall 2015. A parallel government investigation about regulation of for-profit providers in public services, to be presented in spring 2016, may have more important effects regarding the future mix of private and public owners in primary care. In addition to 
politically sensitive issues around the public-private mix, regulation of for-profit providers and whether private equity companies are legitimate owners of health care providers, county councils struggle with the same issues around the development of primary care as in many other countries. The need for increased capacity and improved integration with both hospital care and municipality services of nursing home and home care are important challenges. An additional challenge is to develop primary care as a natural first-point of contact for the population, without introducing formal gate-keeping not supported by the general population, especially in urban areas.

\subsection{Finland}

There have been many initiatives aiming to improve the quality and volume of primary health care. The previous government attempted this by means of a reform covering the entire health and social care system; however; its proposal was not accepted in Parliament in March 2015. The programme of the current government states that the new structure for social welfare and health care services will be based on autonomous areas larger than the municipalities. These new areas (maximum number 19) will be responsible for arranging all public social welfare and health care services, and the regional decisions will be made by elected councils. A government bill will be prepared on the implementation of the reform in 2016.

As a consequence of the incapability to make political decisions at the government level, a substantial quantity of local projects and experiments working in different directions have been implemented. These initiatives include e.g., (usually small) municipalities buying all health services from private firms. Another direction includes merging health centres and hospital districts into a single organisation (federation of municipalities) that provide all health and social services for inhabitants of the municipalities in the area. Certain hospital districts have established primary health care units, which, promote co-operation and work division between hospitals and health centres, and develop treatment and rehabilitation chains; follow and assess primary health care in the area and the development of its activities and structures; co-ordinate research and development activity in the health centres; coordinate health promotion in the area; and plan and develop the undergraduate and postgraduate training of physicians.

\subsection{Iceland}

In Iceland, there is focus on efficiency and the lack of clearly defined roles for the GP sector. Consequently, reforms are aimed at moving from salaried GPs towards capitation, increases in private provision and increased competition.

There is development toward more equal opportunities for private providers compared with public ones in Iceland as a means of providing incentives for efficiency. Currently, the Ministry of Health is managing the project "Better healthcare 2013-2017", and one of the project's tasks is to implement risk-adjusted capitation for financing of health centres (inspired by primary care providers in Sweden). This capitation has been applied to an extent with the two privately run health centres in Reykjavík. It is not on the government's agenda to implement a gate-keeping system, although one of the objectives of the current healthcare project is to make primary care a first point of contact. One prominent argument against gatekeeping in primary care in Iceland is the lack of GPs, although Iceland does not appear to have fewer GPs per capita than many Nordic countries. However, there are concerns over future lack of GPs due to the age structure of current GPs.

Certain features of the new public management (NPM) are developing in Iceland; intra-public sector competition (on agenda to increase privately managed health care centres 
although the public-private mix is debated) and purchaser-provider separation (the Icelandic Health Insurance). The development of the private sector is based on contracts between the state and the providers. Although the goal of increased variety in production of health services is attractive, because increased competition could result in a more efficient production, it simultaneously calls for tighter control of services and providers by means of regulation and evaluation to ensure a homogeneous high-quality services. For effective evaluation and quality measures, comprehensive IT systems are required. Such IT systems have not been developed in Iceland.

\section{Discussion}

The first thing that strikes us when reading through the previous sections of this paper is that the Nordic countries are very different regarding General Practice. As an example, certain Nordic countries use General Practice as a mandatory first point of contact (gate keeper) to steer the patient flow between primary and secondary care, whereas others do not. GPs are, to varying degrees between the countries, publicly employed, private practitioners or a part of the occupational health care. In Sweden, corporate ownership is allowed, which provides a completely different structure than individual ownership. Remuneration schemes are, in certain countries, based on national contracts, whereas others rely on decentralised and diversified systems. Most countries have had relatively modest changes in the sector historically but much current political focus. Sweden appears to differ from the other countries in the sense that they have previous experience with many of the issues that are being discussed in the other countries. These experiences include differentiated capitation, pay for performance, corporate ownership, use of electronic health records and feedback on quality performance.

No remuneration system is perfect and each has its negative side-effects. Activity based systems have the risk of oversupply, salaried systems have the risk of undersupply. When examining the remuneration structures and the ongoing reforms and political debates in the Nordic countries, it appears to be the case that the focus is on controlling the sideeffects of the remuneration system in operation. Certain countries that operate private practices with largely activity based remuneration are introducing more budget control, monitoring and authority information systems, which are reducing the autonomy of GPs. It has been shown that many GPs have changed their preferences from private practice to salaried practice (Holte, Abelsen et al. 2015). Iceland operates a public system with salaried GPs but is introducing capitation funding and attempting to increase competition to increase the efficiency. Countries with salaried systems with geographical responsibility are introducing more choice for patients and incentives for private practice. Countries with systems largely based on private practice are introducing more monitoring and public regulation to control budgets. Additional observations are that new governments appear to have different views on the future organisation of primary care, which tend to provide much political tension but lead to few changes in actuality. Interestingly, Sweden appears to be the most innovative in relation to introducing new incentive schemes, perhaps because decisions are made at a more decentralised level.

The huge variation among the Nordic countries creates the possibility of studying most of the central questions of primary care. This includes some of the following questions

- Are gate keeping systems having a rationing effect on specialised care utilization?

- Are salaried practices less efficient than private practice?

- Does differentiated capitation reduce patient inequity in access, and does it reduce the workload of physicians in deprived areas? 
- Would P4P be effective in the Nordic systems?

- Can non-financial incentives such as quality programmes linked to EHR or the use of quality feedback reports change physicians' behaviour?

The Nordic countries have excellent register data to study these questions in observational studies; however, to be able to be really exceptional, we need to find the means to draw causal inference on the effects of various organisational arrangements. Hence, an important task would be to assess whether certain developments in the Nordic countries can be assessed as natural experiments. If this is not the case, it raises the important question as to what extent the Nordic countries can act as a control group for each other. If this is the case, many interesting studies could be conducted. However, a considerable amount of work would need to be done beforehand to ensure that primary care practices were sufficiently comparable.

\section{Conclusions}

Despite the many similarities within the Nordic health care systems, the primary care sectors work in highly different arrangements. Most important is the split in gate-keeping/no gatekeeping, private versus salaried practices, possibilities for corporate ownership, skill mix and the organisational structure. Current reforms and political agendas appear to be focusing on the side effects of the individual countries' specific systems.

\section{Acknowledgments}

Financial support from the Nordic Research Council (project grant no: 229987/F10) is gratefully acknowledged.

\section{References}

Allard, M., I. Jelovac and P. T. Leger (2011). Treatment and referral decisions under different physician payment mechanisms. J Health Econ 30(5): 880-893.

Anell, A. (2014). Jämförelse mellan almen praksis i Region Sjaelland och primärvård i Region Skåne, Institutet för ekonomisk forskning vid Lunds Universitet. 3.

Anell, A. (2015). The public-private pendulum--patient choice and equity in Sweden. N Engl J Med 372(1): 1-4.

Eijkenaar, F., M. Emmert, M. Scheppach and O. Schoffski (2013). Effects of pay for performance in health care: a systematic review of systematic reviews. Health Policy 110(2-3): 115-130.

Evans, R. G. (1974). Supplier-Induced Demand: Some Empirical Evidence and Implications, The Economics of Health and Medical Care. International Economic Association, MacMillian.

Gosden, T., F. Forland, I. S. Kristiansen, M. Sutton, B. Leese, A. Giuffrida, M. Sergison and L.

Grytten, J., F. Carlsen and R. Sorensen (1995). Supplier inducement in a public health care system. $J$ Health Econ 14(2): 207-229.

Grytten, J. and R. Sorensen (2001). Type of contract and supplier-induced demand for primary physicians in Norway. J Health Econ 20(3): 379-393.

Grytten, J. and R. Sorensen (2007). Primary physician services-list size and primary physicians' service production. J Health Econ 26(4): 721-741.

Grytten, J. and R. Sorensen (2008). Busy physicians. J Health Econ 27(2): 510-518.

Harrison, M. J., M. Dusheiko, M. Sutton, H. Gravelle, T. Doran and M. Roland (2014). Effect of a national primary care pay for performance scheme on emergency hospital admissions for ambulatory care sensitive conditions: controlled longitudinal study. BMJ 349: g6423. 
Holte, J. H., B. Abelsen, P. A. Halvorsen and J. A. Olsen (2015). General practitioners' altered preferences for private practice vs. salaried positions: a consequence of proposed policy regulations? BMC Health Serv Res 15: 119.

Iversen, T. (2004). The effects of a patient shortage on general practitioners' future income and list of patients. J Health Econ 23(4): 673-694.

Iversen, T. and H. Luras (2000). The effect of capitation on GPs' referral decisions. Health Econ 9(3): 199-210.

Jia L, Yuan B, Meng Q, Scott A. Payment methods for ambulatory care health professionals (Protocol). Cochrane Database of Systematic Reviews 2015, Issue 9. Art. No.: CD011865. DOI: 10.1002/14651858.CD011865.

Kantarevic, J., B. Kralj and D. Weinkauf (2011). Enhanced fee-for-service model and physician productivity: evidence from Family Health Groups in Ontario. J Health Econ 30(1): 99-111.

Kolstad, J. T. (2013). Information and Quality When Motivation Is Intrinsic: Evidence from Surgeon Report Cards. American Economic Review 103(7): 2875-2910.

Krasnik, A., P. P. Groenewegen, P. A. Pedersen, P. von Scholten, G. Mooney, A. Gottschau, H. A. Flierman and M. T. Damsgaard (1990). Changing remuneration systems: effects on activity in general practice. BMJ 300(6741): 1698-1701.

Krasnik, A. and B. Paulsen (2009). Reforming Primary Care: In Magnussen, J., Vranæk, K. Saltman R.B.: Nordic Health Care System: Recent Reforms and Current Policy Change. Berkshire, Open University Press.

Magnussen, J., K. Vrangbæk and R. B. Saltman (2009). Nordic Health Care Systems: Recent Reforms and Current Policy Challenges. Berkshire, Open University Press.

Melding til Stortinget nr. 26 (2014-2015). Fremtidens Primærhelsetjeneste - nærhed og helhet. Helse- og Omsorgsdepartementet. Oslo.

Olsen, K. R. (2012). Patient complexity and GPs' income under mixed remuneration. Health Econ 21(6): 619-632.

Peacock, S. J. and J. R. Richardson (2007). Supplier-induced demand: re-examining identification and misspecification in cross-sectional analysis. Eur J Health Econ 8(3): 267-277.

Pedersen (2000). Capitation, salary, fee-for-service and mixed systems of payment: effects on the behaviour of primary care physicians. Cochrane Database Syst Rev(3): CD002215.

Reed, M., J. Huang, R. Brand, I. Graetz, R. Neugebauer, B. Fireman, M. Jaffe, D. W. Ballard and J. Hsu (2013). Implementation of an outpatient electronic health record and emergency department visits, hospitalizations, and office visits among patients with diabetes. JAMA 310(10): 1060-1065.

Reinhardt, U. E. (1985). The theory of physician-induced demand: reflections after a decade. $J$ Health Econ 4(2): 187-193.

Reinhardt, U. E. (1999). The economist's model of physician behavior. JAMA 281(5): 462-465.

Richardson, J. R. and S. J. Peacock (2006). Supplier-induced demand: reconsidering the theories and new Australian evidence. Appl Health Econ Health Policy 5(2): 87-98.

Scott, A. (2000). Economics of General Practice, Handbook of Health Economics. Amsterdam, Elsevier B.V.

Scott, A. and J. Hall (1995). Evaluating the effects of GP remuneration: problems and prospects. Health Policy 31(3): 183-195.

Starfield, B. m.fl. (2005) Contribution of primary care to health systems and health. Milbank Quarterly; 83(3): 457-502

(C) 2016 by the author(s). This article is an open access article distributed under the terms and conditions of the Creative Commons Attribution license (http://creativecommons.org/licenses/by/4.0/). 